\title{
Mor Lam Mu Dancing Groups: A Career Conservation and Development Model
}

\author{
Piyasuda Pecharawech ${ }^{1}$, Sastra Laoakka ${ }^{1} \&$ Pattamawadee Chansuwan ${ }^{1}$ \\ ${ }^{1}$ The Faculty of Cultural Science, Mahasarakham University, Khamriang Sub-District, Kantarawichai District, \\ Maha Sarakham, Thailand \\ Correspondence: Piyasuda Pecharawech, The Faculty of Cultural Science, Mahasarakham University, \\ Khamriang Sub-District, Kantarawichai District, Maha Sarakham 44150, Thailand. E-mail: \\ aom3221@hotmail.com
}

Received: June 10, 2013 Accepted: July 29, 2013 Online Published: September 29, 2013

doi:10.5539/ass.v9n13p132 URL: http://dx.doi.org/10.5539/ass.v9n13p132

\begin{abstract}
Mor Lam Mu is a performance art specific to Northeastern Thailand and is particularly popular in the provinces of Khon Kaen and Maha Sarakham. This research analyses the background and conditions of Mor Lam Mu with the specific aims of studying the adaptation and maintenance of dancing careers in Mor Lam Mu and creating a conservation and development model for dancing careers in Mor Lam Mu. The research finds that careers in Mor Lam $\mathrm{Mu}$ are becoming increasingly popular as people return to the Northeast in the wake of economic crisis and natural disaster. However, with increasing numbers of performers and the higher competition they generate, modern Mor Lam Mu ensembles have to respond to social and cultural changes in order to survive. This means that the original customs have had to be altered and the traditions of Mor Lam Mu are in danger of disappearing. The development model created according to the results of this study can be used to conserve and promote careers in Mor Lam Mu dancing groups so that they may harmonize traditional customs and modern trends in the future.
\end{abstract}

Keywords: Mor Lam Mu, dancing, conservation, development, career, model

\section{Introduction}

Mor Lam is a very popular artistic performance that is part of the culture of Northeastern Thailand (Isan). Mor Lam plays an important role for the people in rural Isan society. Mor Lam has entertainment and relaxation value for the people of Isan and allows them to forget the stresses of work. The performances instill feelings of joy and impress the audiences with their harmony and deep-meaning language and expression. The performances educate and impart knowledge upon the viewers, providing moral perspectives for the people. The performances show wit and wisdom in their verses and offer solutions to problems. Mor Lam is a part of local art culture and has value for that locality. It is popular for Mor Lam acting performances to retell literary works or local folk stories, which allows the audience to learn about history and take part in the automatic inheritance of the stories. Mor Lam performing is a profession that generates income for actors to support their families (Pimsen, 2003).

Evolution of Mor Lam in Isan has been continuous in content, format and music of the performance. Mor Lam that has been developed and altered from the original style is known as Mor Lam Brayuk ('adapted Mor Lam'), which has been adapted to coexist in harmony with social and cultural changes that affect the everyday life of Isan people (Detpimon, 1978, p.31). The development and adaptation of Mor Lam performance style began with the incorporation of Thai country music and the creation of Look Tung Mor Lam. This performance alternates between Mor Lam dancing and Thai country-style singing. There are also comedy performances on stage and the arrangement is the same as a Thai country music arrangement. The dance postures have been adapted for the rhythm of the song and music, there are dancing group performances as part of the show and modern music is incorporated with traditional Mor Lam singing, using international instruments such as organs, guitars, bass guitars, drum kits and trumpets.

The Rangsiman Mor Lam Mu ensemble was the first ensemble in Thailand to use dancing groups in performances before the Mor Lam show. This style came from the Thai country music groups of Wipot Petsupan and Surapon Sombatjaroen. The style originated with the female Mor Lam performers in the Rangsiman ensemble, dancing to Thai country music. Other Mor Lam groups adopted Rangsiman's innovation and 
continually developed the style, according to audience popularity and market demands. When Mor Lam entered the entertainment business, there was an increase in the investment capital required to produce shows. This stemmed from the popularity of the dancing group performance among the audience. The Mor Lam ensembles have thus adapted and developed the format of the show, costumes, number of performers and dance postures to be more beautiful, stimulating and thrilling. This caused the investment capital required for production to increase. Thus, benefactors and sponsors have a greater role in defining the levels of entertainment, pace and modernity, creating competition between the dancing group shows and causing more serious levels of training and instruction to generate differences from other Mor Lam ensembles (Weerapoon, 1992, p.11).

In the past, dance groups were a component of Mor Lam Ploen, which was simply a dancing and singing performance. The dance group would previously have performed at the end of the main production. Over time, the Thai country ensembles developed the production so that the singers who were not involved with the current show would participate in playing percussion instruments to keep the timing of the music. This format was then developed so that the singers stopped playing instruments and took to the stage to dance in modern styles, wearing more beautiful costumes. Dance group performance is another part of Thai culture that is influenced by social change, which causes continuous development and adaptation of style and materials. The dance postures are part of the identity of Isan people but when modern dances are incorporated into the productions in line with current popular trends, the traditional postures decline. The combination of these modern dances with the local traditions still proves sufficiently popular with the audiences, who are happy to see spectacular dancing shows (Chansuwan, 1999, p.4). Mor Lam ensembles have adapted the format of the performance by adding Thai country-style music to the first part of the show. These alterations have caused the dance group performances to be the highlight of the production and, by implication, the most important part. This is because the dancing group performance opens the Mor Lam production to attract the audience, both male and female, young and old. These people come to watch the show for the dancing and acting and to see the beauty and excitement of the format, costume and performance postures (Anantarak, 1991, p.104).

The audience popularity that has seen the dancing group advance to the starring act has also caused increased competition to gain a territorial advantage in the market. Ensembles have sent their dance instructors to further their education at performance arts institutes or observe popular domestic and international performing artists. Ensemble workers have also been sent to study costume design of Thai country-style performers that can be adapted for use in Mor Lam productions (Chansuwan, 1999).

The most prominent and popular ensembles at the current time are from Khon Kaen and Maha Sarakham Provinces. These include the Mor Lam Mu ensembles of Rattanasin Intra Thairat, Prathom Banteung Sin, Rabieb Watasin, Nongmai Meuang Chumpae, Gaen Nakhorn Banteung Sin and Saonoi Petban Peng. These ensembles have all won awards from government sector Mor Lam contests. These contests are a way of measuring the success of the productions and cause a trend of continual development, reflecting the capital and budget of the ensemble and its sponsors. Positive competition results increase the business and income of the ensembles, thus enabling the dancers to treat their work as an occupation and generate an income. For example, the Rattanasin Intra Thairat ensemble has eighty dancers, the Prathom Banteung Sin ensemble has ninety dancers and the Rabieb Watasin ensemble has eighty dancers. These dancers can command a fee between two-hundred-and-eighty and three-hundred-and-fifty baht per performance.

The behavior of Isan audiences has also changed due to the global economic recession and the worst domestic flooding in Thai history. There has been internal migration from Bangkok and provinces in the affected areas to original hometowns. This has caused the dancing profession to increase in popularity as a viable source of income for those people returning to Isan in the wake of the economic crisis.

For these reasons, the importance and role of the dancing group in the Mor Lam production has continually developed according to social and cultural change and will continue to develop in the future. The researchers thus saw the importance of conserving and developing the career of dancing group performers in order to make it suitable for Thai society. The researchers considered it especially important to make the dancing group performances suitable for Isan culture and society, which have ancient and unique identities and are able to provide opportunities for work and income. In the midst of current cultural and social change that is caused by the penetration of external cultures into Thai society, it is thus necessary to study Mor Lam Mu Dancing Groups: A Career Conservation and Development Model. This is in order to investigate the development and knowledge of dancing groups in Mor Lam Mu productions, the adaptation of the shows, the maintenance of the dancing profession and a conservation and development model for dancing careers in Mor Lam Mu. It is a part of local culture and wisdom that must remain as part of the Thai identity, must be inherited by future generations and must be used to benefit the economy and society in creating innovations of value and service. This will help 
develop the quality of life among people in the community for the future.

\section{Research Aims}

This research has three primary research aims: a) to study the development and knowledge related to dancing careers in Mor Lam Mu; b) to study the adaptation and maintenance of dancing careers in Mor Lam Mu; c) to study a conservation and development model for dancing careers in Mor Lam Mu.

\section{Research Methodology}

This is a qualitative research. The research area and population were selected using a purposive sampling method. A survey was undertaken to select the research area from the twenty provinces officially recognized by the government as part of Northeastern Thailand (Isan). The provinces selected were home to Mor Lam Mu ensembles with dancing groups. Ultimately, two provinces fit the criteria: Khon Kaen and Maha Sarakham. The ensembles selected for study were chosen based on the popularity of their performance; the ensembles with the largest number of performances per year were selected for the study. These were the ensembles of Rattanasin Intra Thairat, Prathom Banteung Sin, Rabieb Watasin, Nongmai Meuang Chumpae, Gaen Nakhorn Banteung Sin and Saonoi Petban Peng.

The sample population included people related to Mor Lam Mu ensembles with dancing groups in Khon Kaen and Maha Sarakham Provinces, including leaders or organizers of the ensembles, dance instructors to the ensembles, performers, employers and audiences. The informant groups were selected using a purposive sampling technique according to the objectives of the research and categorized into three groups. The informants provided data regarding the development and knowledge related to dancing careers in Mor Lam Mu, adaptation and maintenance of dancing careers in Mor Lam Mu and the conservation and development model for dancing careers in Mor Lam Mu. The first group of key informants included two national performers in the Mor Lam artistic branch and six Mor Lam ensemble leaders. The second group of casual informants included six Mor Lam $\mathrm{Mu}$ dance instructors and sixty performers (ten per ensemble). The third group of general informants consisted of sixty-six people using the service of the six ensembles, including six employers and sixty members of the audiences.

Data for this research was collected from document study and field research. The research tools used for this research were created from the study of documents related to dancing group performances in Mor Lam Mu and documents with results similar to the theme of study. The tools created by the researchers included general survey, participant and non-participant observation, structured and non-structured interview and focus group discussion.

Following collection of data from the field research, the researchers gathered and organized the data according to the data collection method. The information was then checked for sufficiency and validated by Dengin's 1970 triangulation method, in order to judge the accuracy of data from different locations (Jantawanit, 2003, pp.129-130). There were four stages of validation. The first stage was the testing of various data aspects. These included time (whether data collected at different times provided similar results), place (whether data collected at different places provided similar results) and people (whether data collected from different people provided similar results). The second stage of validation concerned the researchers and tested how each researcher yielded results and tested for any discrepancies in these results. The third stage of data validation was the validation of theories and how the results changed with the implementation of alternative theoretical concepts. The fourth and final stage of validation tested the collection and categorization of data (Chantachon, 2006, p.77). If there were any discrepancies or anomalies, the researchers returned to the field to conduct further data collection.

\section{Results}

\subsection{The Development and Knowledge Related to Dancing Careers in Mor Lam Mu}

The results of the research show that dancing groups in Mor Lam Mu productions have been influenced by the modern popularity of Thai country music. The Mor Lam ensembles adapted in order to survive in modern society. They took the dancing group performances to use before the traditional Mor Lam show and evolved alongside Thai country music, foreign concerts and private theatre productions. The Northeastern region of Thailand has a large Mor Lam presence, causing high levels of competition. The audiences are able to choose which shows they want to visit, so the Mor Lam Mu ensembles have to adapt to survive by finding skilled, reputable instructors for teaching dancing techniques to the performers. In light of this competition, the number of performers has increased as well as the design variations of costumes, modern music, color, light, sound, props and selection of popular music. The dancing group performers on stage have clear roles; females will be fragile, sweet and beautiful, while the men will be strong and tough. There are eight components of the knowledge of Mor Lam Mu: 
a) performers; b) performance style concepts; c) props; d) performance design; e) costume design; f) musical instruments; g) practice; $h$ ) selection of performers.

\subsection{The Adaptation and Maintenance of Dancing Careers in Mor Lam Mu}

Regarding the current conditions of and problems with Mor Lam Mu, there is a lack of female performers, causing the Mor Lam ensembles to use an increased number of male performers to complete the stage performance. There is also evidence of different cultures being incorporated within the shows. The desires of the audience and the changes to society and culture have caused adaptations to the color, light and sound formats of the performance by introducing modern innovations and technology. The designs of the costumes have been improved with higher quality material and the dancing group shows have been adapted to keep up-to-date with modern society.

There are four concepts of adaptation within the ensembles: a) adaptation of the performers, dance postures, music and performance according to audience popularity; b) adaptation of costumes, materials and props, publicity techniques, salaries and performer benefits according to the economy; c) adaptation of principals and beliefs surrounding respect of teachers, practice, social rules, salaries and benefits according to society and culture; d) adaptation of Thai culture, local culture and ethnic culture usage according to government policy in order to maintain their position in society and occupations by using local wisdom that is part of the national identity.

\subsection{A Conservation and Development Model for Dancing Careers in Mor Lam Mu}

The conservation and development model for dancing careers in Mor Lam Mu can be summarized in the following figures 1 and 2 .

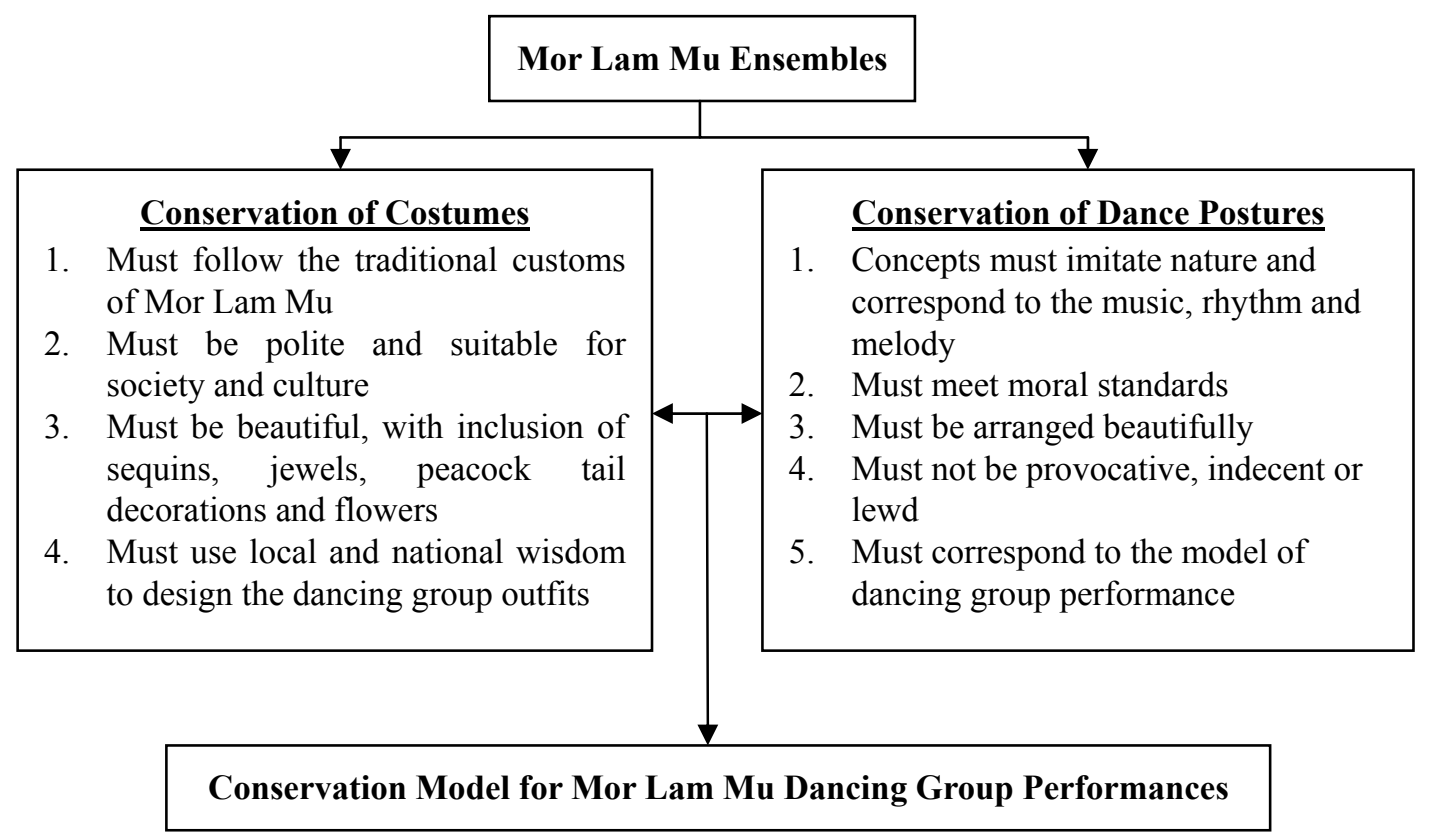

Figure 1. Conservation model for Mor Lam Mu dancing group performances 


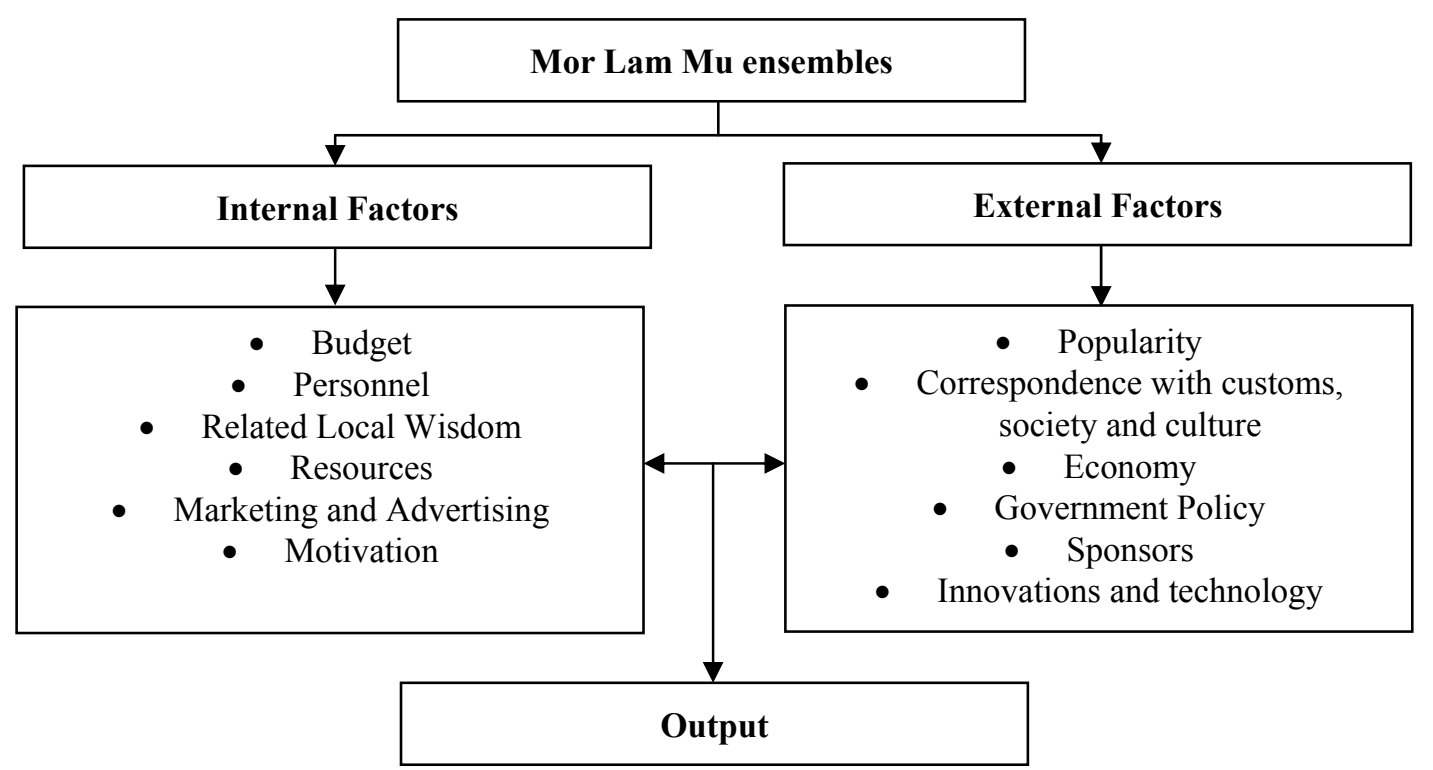

Figure 2. Career development model for Mor Lam Mu dancing group performances

\section{Conclusion}

From the results, this research can be concluded in two parts. Firstly, the dancing group performance is one part of the Mor Lam Mu production. It is a part of the performance culture of Isan people that has been developed over time from everyday life, customs and local wisdom. The art form continually develops according to modern conditions. The important components in the development of dancing group performance are: a) performers; $b$ ) performance style concepts; c) props; d) performance design; e) costume design; f) musical instruments; g) practice; h) selection of performers.

Aside from this, adaptation and maintenance of careers in Mor Lam Mu dancing groups depend on the current situation and problems with Mor Lam Mu dancing group performances, which relate to the popularity of the performance among the audience, the economy, society, culture and government cultural policies.

From the results of this research, a career conservation model for Mor Lam Mu dancing group performances was created. This model was divided into two areas, the conservation of costumes and the conservation of dance postures. Additionally, a career development model for Mor Lam Mu dancing group performances was identified that can be used to develop the Mor Lam Mu ensembles by focusing on internal and external factors in the production of performances. The development model can be used to conserve and promote careers in Mor Lam $\mathrm{Mu}$ dancing groups so that they may continue in the future.

\section{References}

Anantarak, S. (1991). Analysis of Lam. Srinakharinwirot University: Prasanmit Publishing.

Chansuwan, P. (1999). Development of Mor Lam Mu dancing groups in Khon Kaen. Maha Sarakham: Mahasarakham University.

Chantachon, S. (2006). Cultural Qualitative Research. Kalasin: Prasan Publishers.

Detpimon, K. (1978). Pictures reflecting the life of Isan people from Mor Lam. Bangkok: Silpakorn University.

Jantawanit, S. (2003). Qualitative Research Method. Bangkok: Dansunta Publishers.

Pimsen, P. (2003). Mor Lam Mu Wat Khon Kaen. Khon Kaen: Khon Kaen Cultural Center.

Weerapoon, P. (1992). Mor Lam Mu dancing group performances. Maha Sarakham: Srinakharinwirot University.

\section{Copyrights}

Copyright for this article is retained by the author(s), with first publication rights granted to the journal.

This is an open-access article distributed under the terms and conditions of the Creative Commons Attribution license (http://creativecommons.org/licenses/by/3.0/). 